\title{
Experimental investigation of fracture toughness in Al 356-SiCp aluminium matrix composite
}

\author{
Mohammad M. Ranjbaran \\ Department of Material Engineering Shahid Rajaee University, Lavizan, Tehran, 16788, Iran \\ mranjbaran@srttu.edu, Tel: +98-912-1260451 ; Fax: +98-21-22970052
}

\begin{abstract}
The developed aluminum matrix composite (AMC) is considered to be a promising material for low and high-temperature applications. Fiber reinforced AMC materials have high specific strength and modules of elasticity, together with excellent heat resistance. This experimental investigation was initiated to study the low-toughness fracture in Al 356-SiCp (silicon carbide particles) with respect to the role of the various elements of the microstructure and their probable contribution. The fracture in this composite is studied experimentally, in terms of fracture toughness testing. The low-toughness fracture is believed to be an inherent property of this composite and is caused mainly by the differential elastic and thermal properties of the two constituents. These differentials degrade the matrix alloy near the interface by its strain hardening capacity and by stress intensification introduced by the SiC particle geometry. Consequently, the matrix near the interface is subjected to high localized damage leading to premature fracture. It is found that the matrix alloy controls both flow properties and fracture in the materials investigated. It is concluded that a higher toughness composite requires a proper choice of constituent properties which dominate the stress state at the interface.
\end{abstract}

\section{Keywords: Fracture Toughness, Silicon Carbide INTRODUCTION}

The measurement of valid plane strain fracture toughness, $\left(K_{1 C}\right)$ values for particulate reinforced metal matrix composites is an important step in the process of developing useful products from these materials and increasing confidence in their properties and performance. The value of the KIC characterizes the fracture resistance of a material in the presence of a sharp crack under tensile loading, where the state of stress near the crack front is a triaxial plane strain, and the crack-tip plastic region is small compared with the crack size and specimen dimensions (1-5).

In this study, the mechanical behavior and lowtoughness fracture of $\mathrm{Al} 356-\mathrm{SiC}$ particulates $\left(\mathrm{SiC}_{\mathrm{p}}\right)$ was investigated. The objective was to investigate and pursue the main factors contributing to and responsible for the observed low values of fracture toughness and ductility of this composite. This study was initiated because the observed low-toughness fracture in this composite limits their use in potential applications, in spite of other improvements achieved in mechanical properties. The tendency for fracture rather than flow involves a complex

interaction between material microstructure and the loadings $(6,7)$. Consequently, the current work included an investigation of some of the micro structural features of Al $356-\mathrm{SiC}_{\mathrm{p}}$, and the constitutive response due to external loading. Alteration of material microstructure included volume fraction of $\mathrm{SiC}$ particles and matrix. Upon strengthening this alloy by $\mathrm{SiC}$ particles, a decrease in the tensile ductility takes place. Consequently, the interaction between effects of matrix alloy and $\mathrm{SiC}$ on the mechanical behavior and fracture remains to be determined. There is an increased dislocation density in the matrix due to its higher coefficient of thermal expansion than silicon carbide reinforcements. Additionally, strength, modulus, and fracture resistance is improved along with a higher useful working temperature (4). The poor tensile ductility and low fracture toughness was found to be the main disadvantage of this composite. The micro structural complexity has made it difficult to characterize the mechanical behavior and the associated low toughness fracture in this composite. This is attributed mainly to the tangled microstructure resulting from the existence of a high volume fraction of a reinforcement and debris in the matrix alloy. Moreover, the kinetics of precipitation hardening in this composite was found to be 
different from the base alloy $(5,8)$.

Raw Material and Preliminary Work: The materials used in this investigation have a matrix alloy, Al 356 with $0 \%, 10 \%$ and $20 \%$ volume fractions of the $\mathrm{SiCp}$ (silicon carbide particulate) reinforcements. The

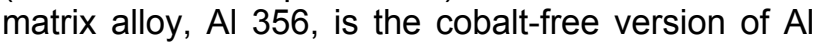
356. The processing route for manufacturing materials is powder metallurgy (P/M) based composites. Since the material used in this investigation was similarity fabricated, effects of the manufacturing parameters on any differences in mechanical properties between samples can be ignored. The reinforcements incorporated in the $\mathrm{Al}$ matrix are of the $\alpha$-type $\mathrm{SiC}$, which is less expensive than the $\beta$-SiC. The chemical analysis showed that actual volume fractions of $\mathrm{SiC}$ particulates were $0 \%$, $11 \%$ and $21 \%$ in the extrudes. The chemical composition of the matrix alloy, $\mathrm{Al} 356$ is shown in Table 1. The tensile properties of the materials, obtained revealed that these composites were adequately isotopic if the tensile properties along the extrusion $(\mathrm{L})$ and the long transverse $(\mathrm{T})$ directions were compared. Table 2 shows tensile properties of composites.

\section{Table 1. Chemical Composition of Al Alloy A356}

\begin{tabular}{|c|c|c|c|c|c|c|c|c|}
\hline Element & $\mathrm{Zn}$ & $\mathrm{Mg}$ & $\mathrm{Cu}$ & $\mathrm{Co}$ & $\mathrm{O}$ & $\mathrm{Fe}$ & $\mathrm{Si}$ & $\mathrm{Al}$ \\
\hline Wt.\% & 5.5 & 2.5 & 1.5 & 0.01 & 0.35 & 0.04 & 0.05 & $\mathrm{Rem}$ \\
\hline
\end{tabular}

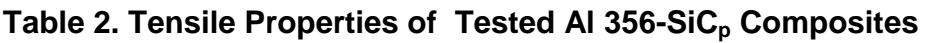

\begin{tabular}{|c|c|c|c|c|}
\hline Material & $\begin{array}{c}\mathrm{E} \\
(\mathrm{MPa})\end{array}$ & $\begin{array}{c}\sigma_{y} \\
(\mathrm{MPa})\end{array}$ & $\begin{array}{c}\sigma_{u} \\
(\mathrm{MPa})\end{array}$ & $\begin{array}{l}\varepsilon_{f} \\
(\%)\end{array}$ \\
\hline $0 \% \mathrm{SIC}$ & $\begin{array}{l}74.17 \\
73.76 \\
77.00\end{array}$ & $\begin{array}{l}538.02 \\
523.85 \\
534.00\end{array}$ & $\begin{array}{c}\text { Longitudinal } \\
593.15 \\
572.71 \\
\\
594.21\end{array}$ & $\begin{array}{c}12.50 \\
8.35 \\
\text { Transverse } \\
9.39\end{array}$ \\
\hline $10 \%$ Sic & $\begin{array}{c}85.33 \\
84.45 \\
182.141 \\
86.11 \\
87.26\end{array}$ & $\begin{array}{l}550.33 \\
564.19 \\
571.58 \\
\\
590.96 \\
595.78\end{array}$ & $\begin{array}{c}\text { Longitudinal } \\
608.10 \\
616.44 \\
622.69 \\
\\
611.23 \\
607.56\end{array}$ & $\begin{array}{c}1.32 \\
1.45 \\
1.19 \\
\text { Transverse } \\
0.81 \\
0.68\end{array}$ \\
\hline $20 \%$ Sic & $\begin{array}{l}107.43 \\
105.77 \\
101.11 \\
\\
105.19 \\
105.06\end{array}$ & $\begin{array}{c}580.33 \\
614.49 \\
580.09 \\
\\
600.76 \\
\ldots \ldots\end{array}$ & $\begin{array}{c}\text { Longitudinal } \\
648.70 \\
666.74 \\
632.19 \\
\\
621.03 \\
572.56\end{array}$ & $\begin{array}{c}1.42 \\
1.56 \\
1.29 \\
\text { Transverse } \\
0.91 \\
0.78\end{array}$ \\
\hline
\end{tabular}

Micro Structural Study: Specimens utilized in this study were prepared using conventional metallographic techniques. A diamond saw was used for cutting samples from the as-received plates. The specimens were ground using emery papers having different grades. Mechanical polishing was done using the two-micron diamond paste, which was followed by polishing using the 0.5 micron alumina. Polished specimens were examined using optical microscope. Examination included different orientations in the composite materials.
Particle size measurements were conducted for the Al 356-10 and 20\% SiCp material utilizing photographs at a magnification of 400x. The quantitative studies were done at three different locations on the same surface. These locations were randomly chosen to avoid any bias in the obtained results.

Sample Preparation for Crack Testing: The crack propagation testing was conducted for the composite material having 10 and $20 \% \mathrm{SiCp}$. Beside 
measurement of the material toughness, this test aimed at studying the stress and deformations field ahead of the crack tip. Successful crack test was achieved using the specimen shown in Figure 1. These specimens were loaded by a constant displacement using the rotating pin shown in the same figure. Precisely after the onset of crack instability, sudden splitting of the specimen into two halves occurred precluding successful measurement. The complete separation occurred because of the big difference between the stress intensity factor for crack initiation, and crack toughness. The big difference was caused mainly by the blunt machined notch (large notch root radius, $\rho)$. Consequently, as the crack initiates and propagates, the driving force for crack propagation remains higher than the material toughness over the entire crack path resulting in a complete separation. In order to decrease the stress intensity factor at the onset of crack instability, the machined-in notch was fatigue pre-cracked so as to produce a sharper crack tip (notch root radius $\approx 0$ ). This required modification of the specimen geometry, where two holes for fatigue pre-cracking were added as shown in Figure 2. In addition, the specimen width was increased to provide enough room for crack before reaching a critical point, where gross yielding of the non-broken ligament or complete separation may occur. This specimen was loaded using a three piece loading wedge rather than a rotating pin. The modified specimen offered several advantages over the first one. First, pure mode I loading was achieved by eliminating friction forces causing other modes of loading. Second, the compliance of the loading wedge was small and could be ignored (in any case, if the wedge compliance is ignored the results are conservative). Third, the fatigue precracking of these specimens was possible. The fatigue crack enhanced the ability of the specimen to propagating crack, since the crack initiation stress intensity, was substantially reduced from a relatively high value, associated with the blunt machined notch, to the much lower $\mathrm{K}_{\mathrm{IC}}$ value. Fourth, fatigue pre-cracking enabled the measurement of $\mathrm{K}_{\mathrm{IC}}$ (assuming a valid loading rate). The specimens were machined by the electric discharge machining (EDM). Then, the side surfaces were ground and polished to enable their investigation. All the specimens were cut such that the crack propagation direction was in the extrusion direction. Fatigue precracking was conducted using a MTS closed loop servo-hydraulic testing machine set to the following fatigue loading conditions: $\mathrm{R}=0.1 \mathrm{~K}_{\max }=9.0 \mathrm{ksi} \sqrt{\text { in }}$
(11 MPa $\sqrt{m}$ ), and frequency $=10 \mathrm{~Hz}$. R is the stress intensity ratio $\left(\mathrm{R}=\mathrm{K}_{\min } / \mathrm{K}_{\max }\right), \mathrm{K}_{\max }$ and $\mathrm{K}_{\min }$ are the maximum and minimum stress intensities, respectively. The number of cycles used during fatigue pre-cracking ranged from 200 to $400 \mathrm{k}$ cycle, which gave a minimum length of fatigue pre-crack of 0.006 inches $(1.5 \mathrm{~mm})$. The crack length after fatigue pre-cracking, ac, was measured on both sides of the specimen and the average value was calculated. After pre-cracking, the specimen was loaded in a constant crack-opening-displacement (COD) mode. This was done using the two-piece wedge shown in Figure 1 by pushing the tapered pin into the bushing (using a slow speed mechanical machine). The COD was measured along the load line using a point micrometer prior to and after loading. In all tests, pop-in occurred at a given COD value and stable tearing was not observed at all due to the low toughness values of these composites. The onset of crack instability (pop-in) was characterized by two events occurring simultaneously; a sudden decrease in the applied load and an emitted sound accompanying the pop-in. The specimen thickness was measured before and after the test to determine the extent of lateral contraction, if any, which is a good estimation of the degree of plane-strain constraint(2,3). The crack length at the onset of crack instability, $\mathrm{a}_{\mathrm{c}}$, was used in $\mathrm{K}_{\mathrm{lc}}$ calculations. Crack length was measured on the fracture surface at three different locations: at the center of the crack front, and midway between the center and end of the crack front on each side surface of the specimen. The $a_{c}$ was the arithmetic average of these three measurements. To identify the location of crack arrest on the fracture surface, the specimens were fatigue loaded. This fatigue loading was conducted at smaller load amplitudes, e. g. $\mathrm{K}_{\max }=5 \mathrm{ksi} \sqrt{\text { in }}(5.5$ $\mathrm{MPa} \sqrt{m}$ ). The crack length was then measured in a manner similar to that described above for measuring ac. The load-line displacement was measured using a point micrometer which has an accuracy of 0.001 inches $(0.0025 \mathrm{~mm})$.

Value of $\mathrm{K}_{\mathrm{IC}}$ were calculated from the following equations(1):

$$
K_{I C}=\frac{\sqrt{3} E H^{3 / 2} \Delta}{4 \sqrt{\left(1-v^{2}\right)\left(a_{C}+0.6 H\right)^{2}}}
$$

Where $E$ is the elastic modulus, $v$ is Poisson's ratio, $\mathrm{H}$ is one half of the specimen height, and $\Delta$ is the 
load-line displacement at the instant of crack instability. After each test, the obtained value of $\mathrm{K}_{\mathrm{IC}}$ was checked for the test validity by ensuring that the specimen geometry satisfied plane-strain condition. $\mathrm{K}_{\mathrm{IC}}$ were checked to satisfy the following requirements. (3):

$$
\begin{aligned}
B, a_{c} & \geq 2.5\left(\frac{K_{I C}}{\sigma_{0.2}}\right) \\
B & \geq 1.25\left(\frac{K_{I C}}{\sigma_{0.2}+\sigma_{0}}\right)^{2}
\end{aligned}
$$

Where $\mathrm{B}$ is the specimen thickness, $\sigma_{0.2}$ is the $0.2 \%$ offset yield strength, and $\sigma_{0}$ is a material constant for strain rate correction (the material yield strength increases as the strain rate increases due to the existing running crack). Moreover, the validity of $\mathrm{K}_{\mathrm{IC}}$ values was checked further for the requirement given in ASTM standard E 561 (3):

$$
\left(W-a_{c}\right) \geq \frac{4}{\pi}\left(\frac{K_{I C}}{\sigma_{0.2}}\right)^{2}
$$

Where $\left(W-a_{A}\right)$ is the unbroken ligament, $W$ and $a_{c}$ are the specimen width and crack length, respectively. The plastic zone size, $r_{y}$, can be written as:

$$
r_{y}(\text { PlaneStress })=\frac{1}{2 \pi}\left(\frac{K_{I C}}{\sigma_{0.2}}\right)
$$

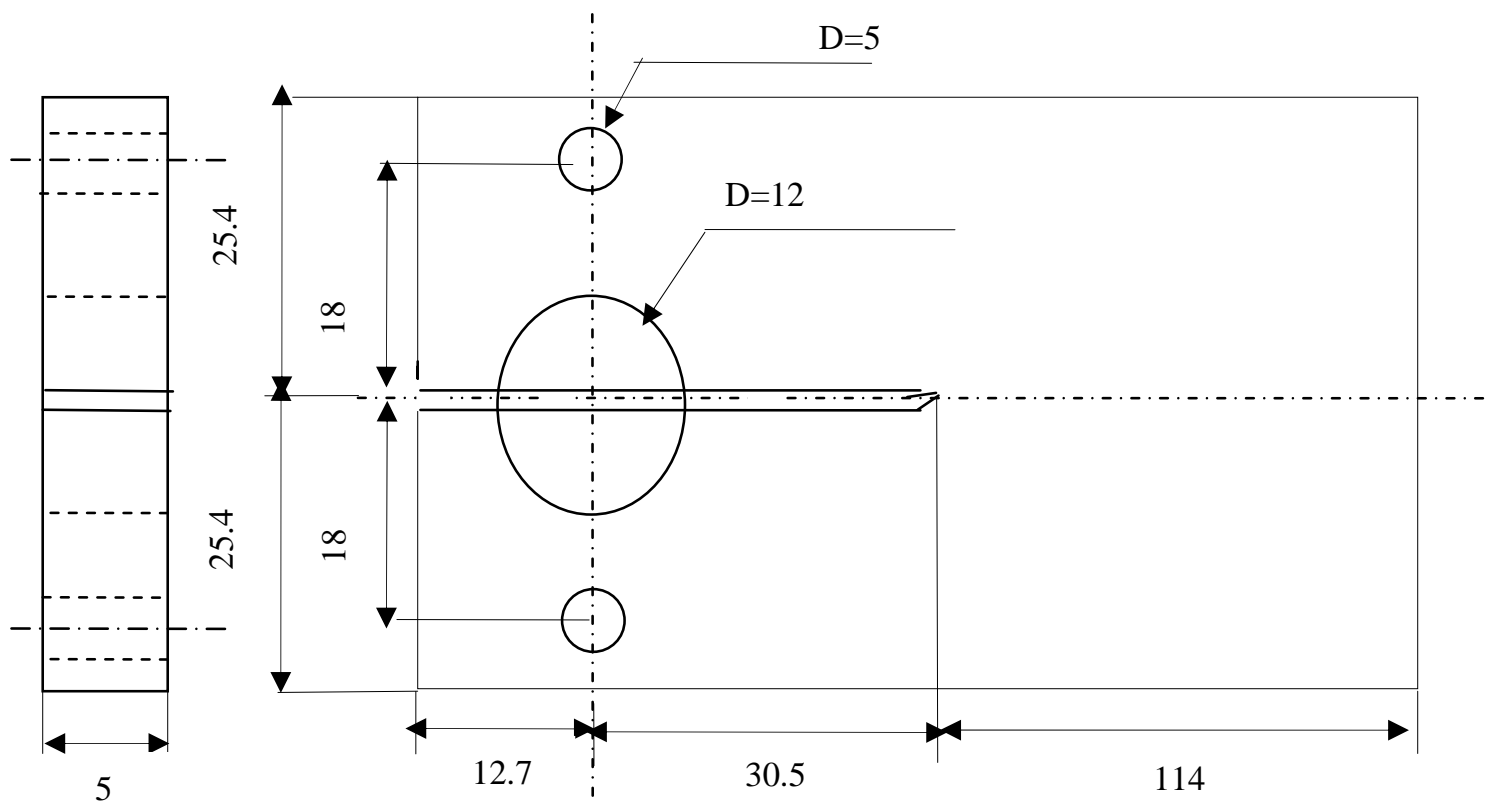

Fig 1. Geometry of Modified Specimen (Dimensions in Millimeter) 
Am. J. Sci. Ind. Res., 2010, 1(3): 549-557

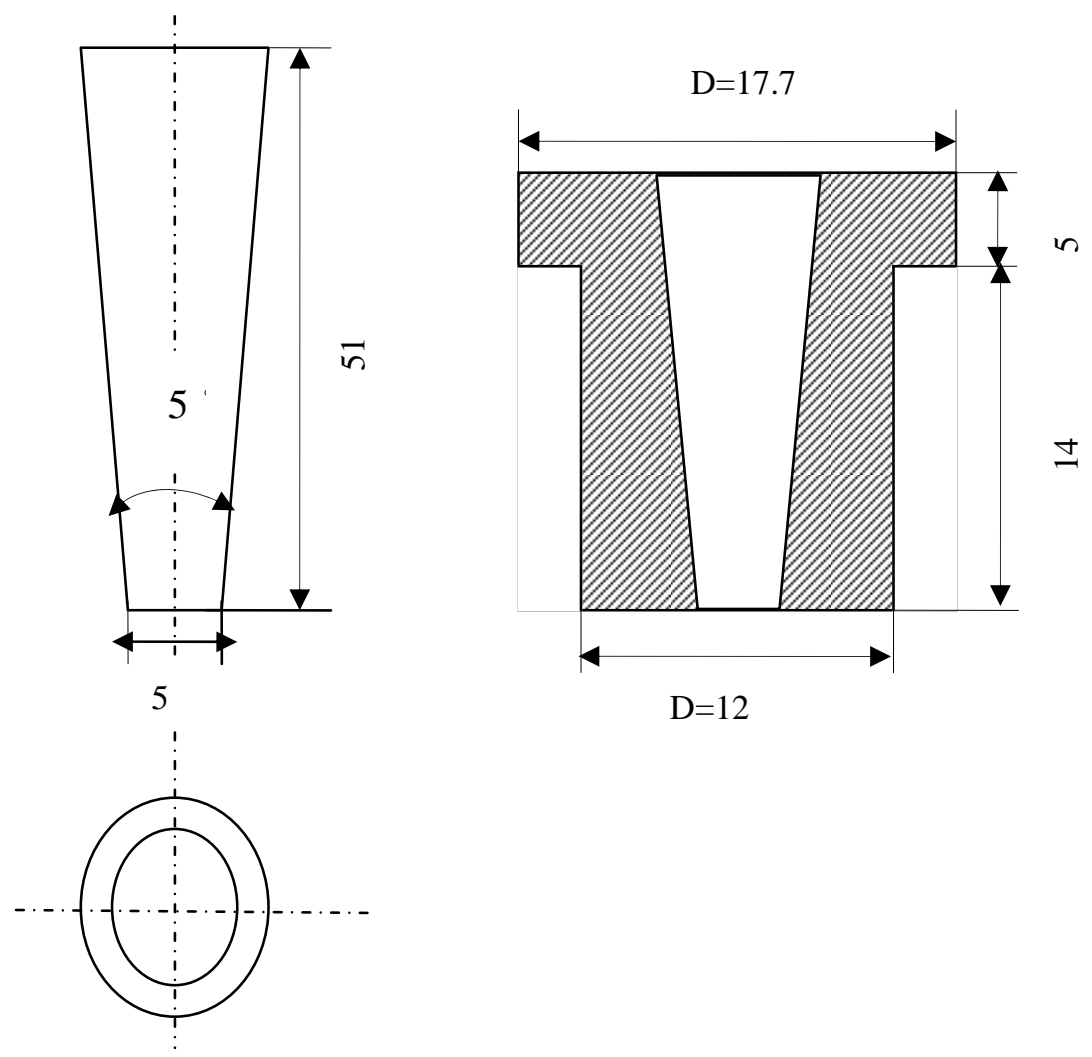

Fig 2. Geometry of the Two- Piece Wedge for Loading Modified Specimen (Dimensions in Millimeter)

\section{RESULTS AND DISCUSSION}

Metallographic examinations of the monolithic material revealed a partially recrystallized microstructure with fine and nearly equated grains. The average grain size was $5.0 \mu \mathrm{m}$ and grain sizes ranging between 3 and $11 \mu \mathrm{m}$ were observed. Typical microstructures for the composites having 10 and $20 \%$ volume $\mathrm{SiC}_{\mathrm{p}}$ are shown in Figures 3 .

The distribution of $\mathrm{SiC}$ particles is non-uniform within the matrix. Agglomerations of these particles in some areas can be observed, while other areas are sparsely populated with reinforcements. Some of the particles show a polygonal shape with sub angular edges, while others have a granular geometry with an aspect ratio of one. The SiC particles are partially oriented in the extrusion direction as a result of the extrusion step. Furthermore, debris of $\mathrm{SiC}$ and particle cracking, which are common features of these MMCs were seen in the microstructure. These 10 and $20 \% \mathrm{SiC}_{\mathrm{p}}$ composite revealed a relatively larger amount of $\mathrm{SiC}$ debris. This debris has been reported to form during processing of $\mathrm{Al}-\mathrm{SiC}$ composites (compaction, consolidation, and extrusion) and degrade the mechanical properties. Figure 3 shows particle size distribution. The SiC particle values are 5.0 to $11 \mu \mathrm{m}$. The most advantageous effect of incorporating $\mathrm{SiC}$ into the $\mathrm{Al}$ 356 matrix was the increase in elastic modulus. The addition of $20 \% \mathrm{SiC}_{\mathrm{p}}$ to $\mathrm{Al} 356$ resulted in an increase in the modulus of elasticity from $10.2 \mathrm{msi}(70 \mathrm{GPa})$ to about $15.5 \mathrm{msi}$ (107GPa). A slight increase was also achieved in the yield and ultimate tensile strengths. On the other hand, the most disadvantageous effect was poor tensile ductility. The crack length was measured using an optical microscope. The value of plane strain fracture toughness, $\mathrm{K}_{\mathrm{IC}}$ was calculated. The calculation of $\mathrm{K}_{\mathrm{IC}}$ was possible by use of fatigue pre-cracking, which develops a sharp crack prior to quasi-static-loading. Table 3 and 4 show calculated values of $\mathrm{K}_{\mathrm{IC}}$, yield stress, elongation and $r_{y}$ for both 10 and $20 \%$ SiC particle. The plastic zone size $\left(r_{y}\right)$ was calculated using obtained values of $\mathrm{K}_{\mathrm{IC}}$ and equation 5. 


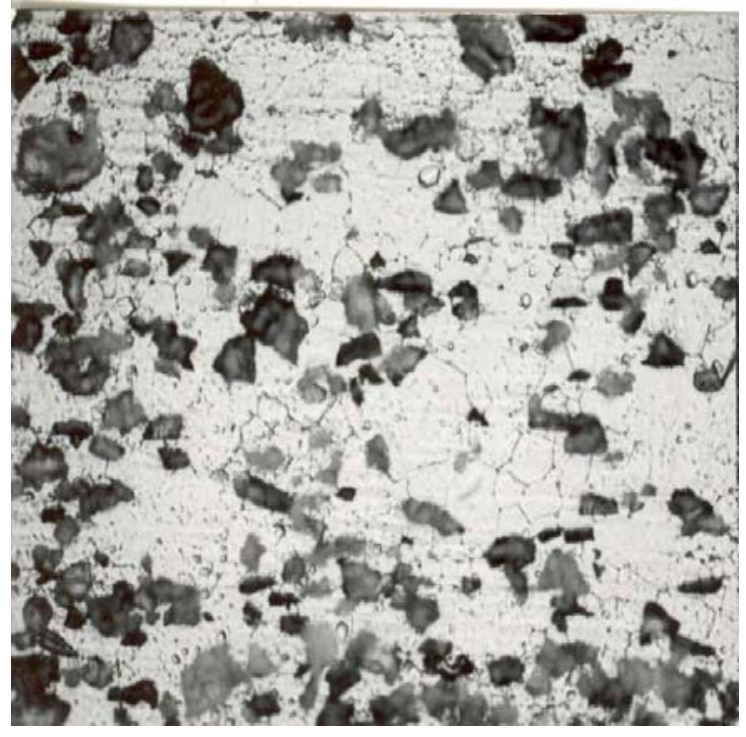

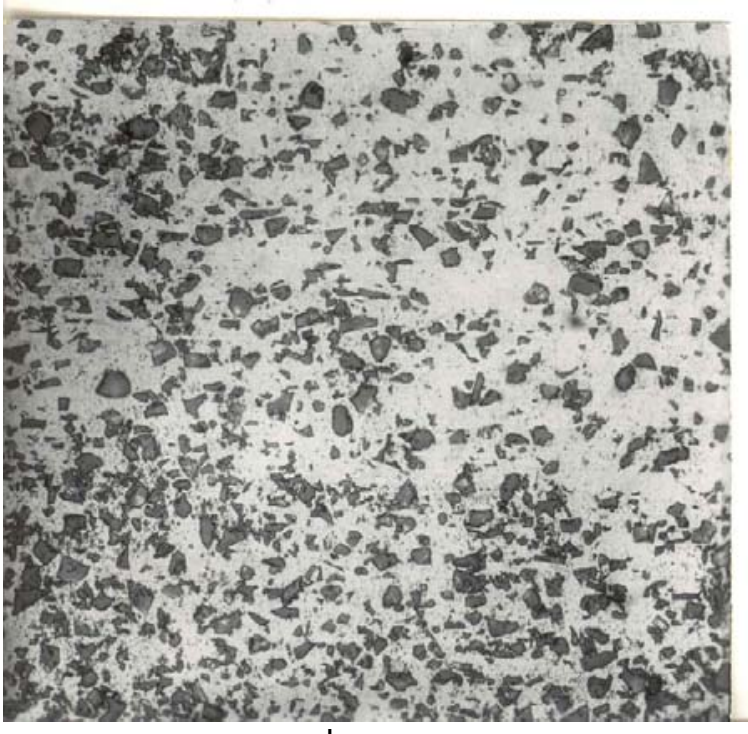

b

Fig 3. Typical Microstructure of the Al 356 a) 10 and b) $20 \%$ SiCp

Table 3. Fracture Toughness Value of Al 356 with $10 \% \mathrm{SiC}_{\mathrm{p}}$ Composite

\begin{tabular}{|l|c|c|c|c|c|c|}
\hline \multicolumn{2}{|l|}{ KIC } & \multicolumn{2}{|c|}{$\sigma_{y}$} & \multicolumn{2}{|c|}{$r_{y}$} & Elongation \\
\hline$M P a \sqrt{m}$ & $(k s i) \sqrt{i n}$ & $M P a$ & $(k s i)$ & micron & mils & $(\%)$ \\
\hline 19.4 & 15.9 & 465.79 & 77.6 & 260 & 10.2 & 1.95 \\
\hline
\end{tabular}

Table 4. Fracture Toughness Value of Al 356 with $20 \% \mathrm{SiC}_{\mathrm{p}}$ Composite

\begin{tabular}{|l|c|c|c|c|c|c|}
\hline \multicolumn{2}{|l|}{ KIC } & \multicolumn{2}{|c|}{$\sigma_{y}$} & \multicolumn{2}{|c|}{$r_{y}$} & Elongation \\
\hline $\mathrm{MPa} \sqrt{\mathrm{m}}$ & $(\mathrm{ksi}) \sqrt{\mathrm{in}}$ & $\mathrm{MPa}$ & $(\mathrm{ksi})$ & micron & $(\%)$ \\
\hline 24.1 & 21.9 & 595.9 & 86.4 & 260 & 10.2 & 1.85 \\
\hline
\end{tabular}

The value of $r_{y}$ for the monolithic alloy $\left(\mathrm{K}_{\mathrm{IC}}=42 \mathrm{ksi} \sqrt{\text { in }}\right)$ was found to be $\left.1151.5 \mu \mathrm{m}\right)$; a value which is almost four times that for $\mathrm{Al} 356,20 \%$ $\mathrm{SiC}_{\mathrm{p}, \text {. }}$ This shows that plastic dissipation work is much less for the composites than for the monolithic alloy. The experimental value $K_{\mathrm{IC}}$ was checked using equations 2, 3, 4 for the test validity in order to ensure that the specimen geometry satisfied plane strain conditions. The particle fracture at critical load is likely caused by stress concentration due to the particle geometry and internal defects, e.g. void which was frequently observed on the fracture surface. Figure 4 is interesting in that it shows a SiC particle, which decohered near the interface and left its replica on the fracture surface. The replica revealed micro voids in the matrix adjacent to the interface, an implication that fracture occurred by void nucleation in the matrix alloy followed by crack propagation at the area adjacent to the interface. This observation indicates that crack propagation occurs preferentially near the interface, and that void growth is severely limited due to the particle constraint.

An intergranular fracture mechanism was also observed, as shown in figure 5. Intergranular particles result from a decreased cohesive strength between grains due to the existence of intermetallic inclusions on grain boundaries. Another predominant fracture mode was the delamitation of oxide intermetallics.

Figures 6 show o fractographs for a fractured crack revealing secondary micro cracks in a plane normal to the major crack plane. This type of micro crack resulted from the delamination of oxide stringers 
introduced in the materials during processing. $\mathrm{MgO}$ and $\mathrm{Al}_{2} \mathrm{O}_{3}$ intermetallics were the most prevalent inclusions associated with this mode of fracture

A large number of micro cracks were created in the stress field associated with the major crack. All secondary micro cracks were associated with SiC particulates, where particle cracking and/or particle decohesion created the associated micro crack, as shows in Figure 7. This observation suggests that $\mathrm{SiC}$ particles adjacent to the interface are the potential sites for micro crack initiation. Moreover, it is likely that crack propagation occurs with the main crack linking secondary micro cracks. Figure 8 shows a typical example of micro crack in the matrix by crack tip blunting. This micro crack had initiated within a $\mathrm{SiC}$ cluster.

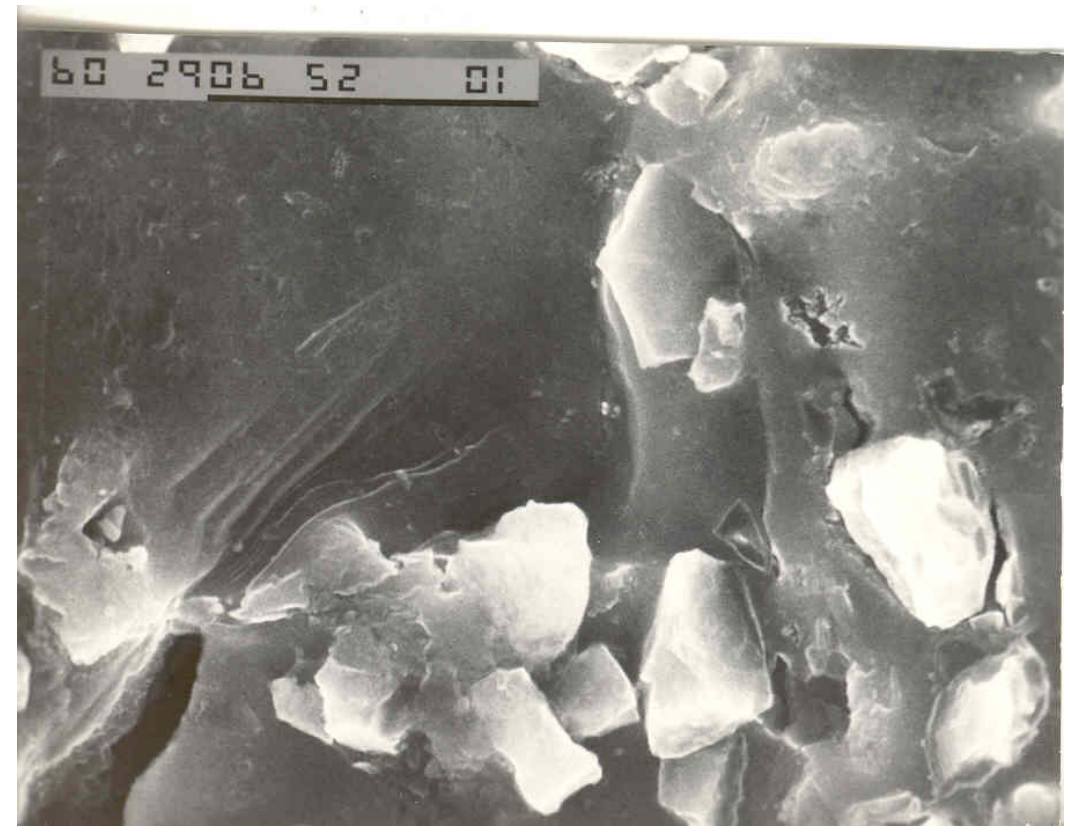

Fig 4. Matrix Failure Adjacent to Al/SiC Interface

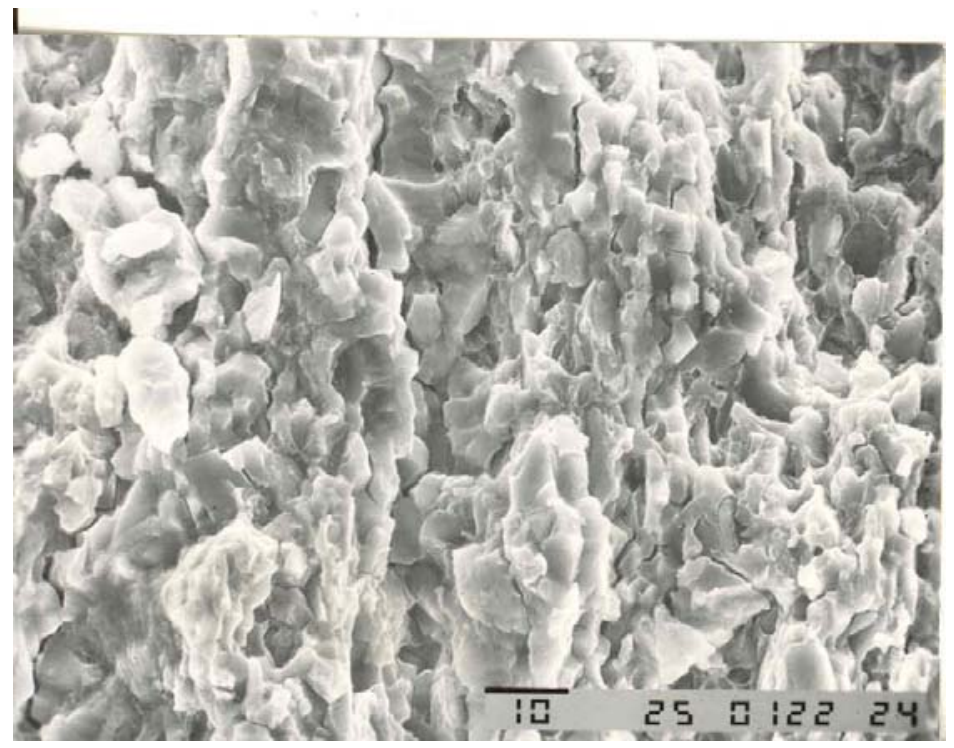

Fig 5. Intergranular Fracture in the Matrix 
Am. J. Sci. Ind. Res., 2010, 1(3): 549-557

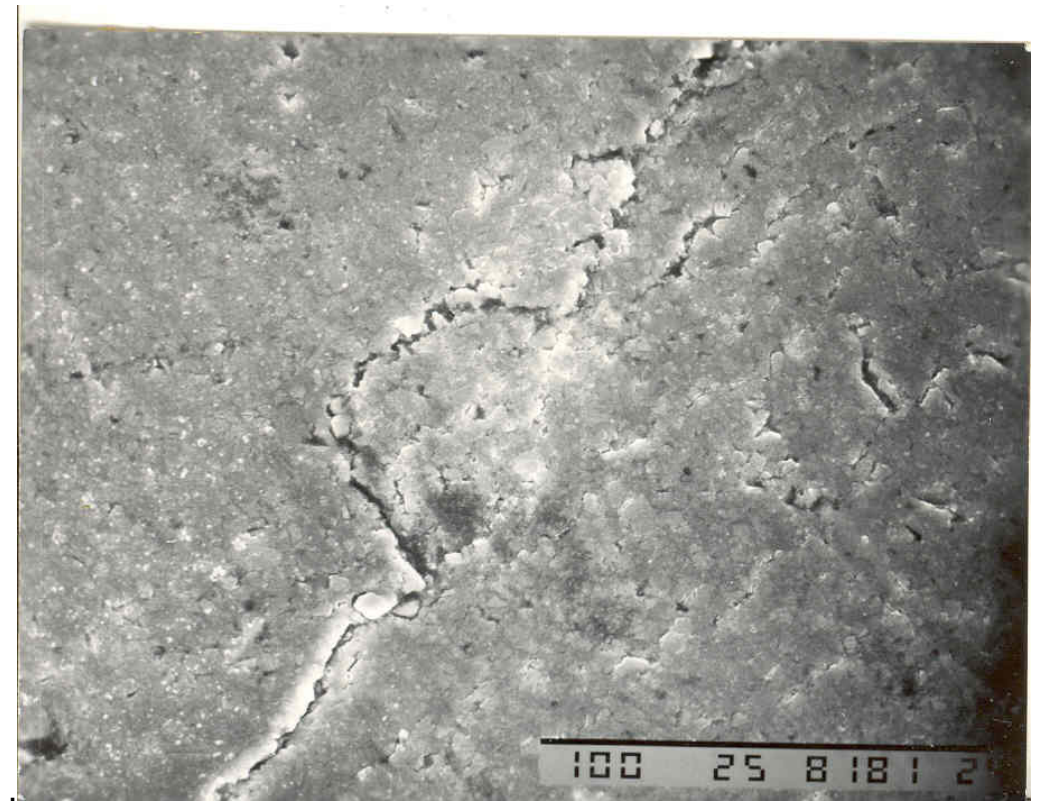

Fig 6. Delamination of Intermetallic Inclusions Observed on the Fracture Surface

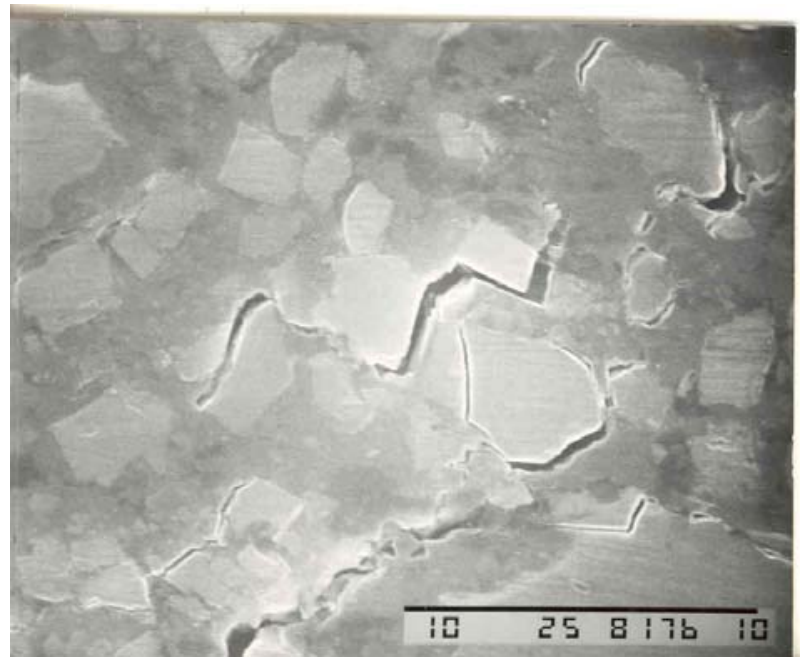

Fig 7. Location of Secondary Micro crack

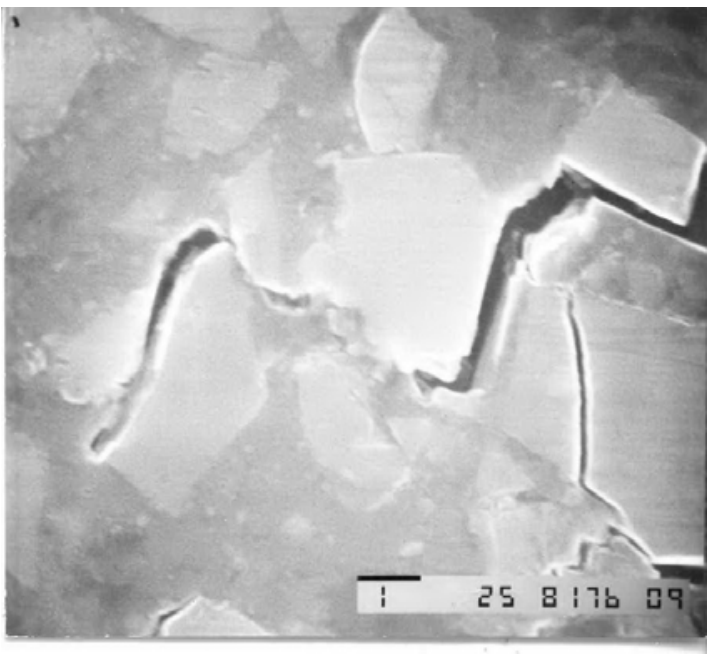

Fig 8. Blunting of Micro cracks in the Matrix 


\section{CONCLUSION:}

This study shows that the failure is initiated by micro void nucleation at the different initiation sites. Void initiation is more pronounced in the matrix near the interface. The micro cracks can grow from these micro voids to absorb available strain energy. Crack propagation occurs by linking these micro cracks locating the crack path preferentially in the matrix adjacent to the interface This study shows that this material must have adequate wettability with both $\mathrm{Al}$ and $\mathrm{SiC}$ to achieve good bonding. Moreover, the proposed material must have high value of tensile ductility and a low yield stress in order to accommodate the plastic strain developed during processing and relax stress concentrations introduced by particle geometry.

\section{REFERENCES}

[1] Juan N. "A Review of Fracture Toughness" Pittsburg State University, August 9, 2006.

[2] ASTM E 399, "Standard Test Method for Plane- Strain Fracture Toughness Testing", Annual Books of ASTM Standard.
[3] ASTM E561, "Tentative Recommended Practice for curve Determination", Annual Book of ASTM Standard.

[4] Lord J. "Fracture Toughness Test Methods for MMC" Volume $10,2007$.

[5] Department of Applied Mechanics," Overview of the Experimental Investigations of the Fracture Toughness in Composite" Budapest University of Technology, Budapest, Hungary, 2005

[6] Hui Z., Zhong Z. Jing Li .Yang K " Temperature dependence of crack initiation fracture toughness of various nanoparticles filled polyamide 66" J. of Polymer, Vol 47, 2006, pp. 679-689

[7] Vazquez Villar, M , Romero-Romo, A. Altamira- Torres and E. , Rocha-Rangel "Microstructure evolution and fracture toughness of $\mathrm{Al} 2 \mathrm{O} / \mathrm{Ti}$ composites", J, of Ceramic Processing Research. Vol. 9, No. 3, 2008, pp. 330-333

[8] Rittle, D, Rosakis, A.J" Dynamic fracture of berylliumbearing bulk metallic glass systems" $\mathrm{J}$ of Engineering Fracture Mechanics, vol 72 , 2005, pp 1905-1919 